\title{
Effect of bronchoalveolar lavage on the clinical efficacy, inflammatory factors, and immune function in the treatment of refractory pneumonia in children
}

\author{
Minqing Pei ${ }^{1 \#}$, Ping Jiang ${ }^{2 \#}$, Tingting Wang ${ }^{1}$, Caifeng Xia $^{1}$, Ruiying $\mathrm{Hou}^{2}$, Ailing Sun ${ }^{1}$, Hui Zou ${ }^{1}$ \\ ${ }^{1}$ Department of Pediatrics, Sunshine Union Hospital, Weifang, China; ${ }^{2}$ Department of Pediatrics, Affiliated Hospital of Weifang Medical College, \\ Weifang, China \\ Contributions: (I) Conception and design: M Pei, H Zou; (II) Administrative support: P Jiang, R Hou; (III) Provision of study materials or patients: M \\ Pei, P Jiang, T Wang, C Xia, A Sun; (IV) Collection and assembly of data: All authors; (V) Data analysis and interpretation: T Wang, R Hou, A Sun, \\ H Zou; (VI) Manuscript writing: All authors; (VII) Final approval of manuscript: All authors. \\ "These authors contributed equally to this work. \\ Correspondence to: Hui Zou. Department of Pediatrics, Sunshine Union Hospital of Weifang, 9000 Yingqian Street, Gaoxin District, Weifang 261000, \\ Shandong, China. Email: ygrhyyekzh890001@163.com.
}

Background: Refractory pneumonia is a special type of pneumonia in children. This study aimed to analyze the effect of bronchoalveolar lavage (BAL) on the clinical efficacy, inflammatory factors, and immune function in the treatment of pediatric refractory pneumonia.

Methods: A total of 196 children with refractory pneumonia admitted to our hospital from January 2017 to January 2020 were enrolled and allocated to a study group ( $\mathrm{n}=99)$ and a control group ( $\mathrm{n}=97)$. The study group was treated with BAL treatment plus conventional treatment, and the control group was treated with conventional treatment. The clinical efficacy, time of fever regression, time of cough relief, and length of hospital stay were compared between groups. Changes in inflammatory factors, immune function, pulmonary ventilation function, and complications were analyzed. The levels of inflammatory factors in BAL fluid were compared.

Results: The times of fever remission, cough relief, and hospital stay of the study group was shorter than those of the control group, and the total clinical effective rate of the study group was higher. At any time after treatment, the levels of interleukin-6 (IL-6), C-reactive protein (CRP), and tumor necrosis factoralpha (TNF- $\alpha)$ in the study group were lower than the control group. After 3-day of treatment, IL-6, CRP and TNF- $\alpha$ in BAL fluid in the study group were significantly decreased compared with before treatment. Immunoglobulin A (IgA) and immunoglobulin G (IgG) levels in the study group were higher than those in the control group at any time after treatment, and immunoglobulin $M(\operatorname{IgM})$ levels were lower than in the control group. The levels of oxygenation index (OI), lung dynamic compliance (Cdyn), and work of breathing (WOB) in the study group were higher than those in the control group at any time after treatment. Conclusions: BAL treatment can effectively relieve the inflammatory response, improve immune function and lung ventilation function in children with refractory pneumonia. The clinical effect is remarkable and worthy of promotion.

Keywords: Fiberoptic bronchoscope alveolar lavage treatment; refractory pneumonia in children; clinical efficacy; inflammatory factors; immune function

Submitted Feb 04, 2021. Accepted for publication Apr 20, 2021.

doi: $10.21037 / \mathrm{tp}-21-89$

View this article at: http://dx.doi.org/10.21037/tp-21-89 
Table 1 Comparison of general data between the 2 groups

\begin{tabular}{lccccc}
\hline Group & Gender (male/female) & Age (year) & Height $(\mathrm{cm})$ & Weight $(\mathrm{kg})$ & Body temperature $\left({ }^{\circ} \mathrm{C}\right)$ \\
\hline Study group $(\mathrm{n}=99)$ & $56 / 43$ & $6.35 \pm 1.51$ & $115.79 \pm 2.85$ & $19.26 \pm 1.85$ & $38.69 \pm 0.87$ \\
Control group $(\mathrm{n}=97)$ & $55 / 42$ & $6.39 \pm 1.56$ & $116.53 \pm 2.51$ & $19.38 \pm 1.89$ & $38.75 \pm 0.89$ \\
$\mathrm{t} / \chi^{2}$ & 0.004 & 0.181 & 1.928 & 0.449 & 0.477 \\
$\mathrm{P}$ & 0.950 & 0.857 & 0.055 & 0.654 & 0.634 \\
\hline
\end{tabular}

$\mathrm{t} / \chi^{2}$, t-test/chi-squared test.

\section{Introduction}

Refractory pneumonia in children a kind of lung inflammation with a protracted disease course, which causes poor clinical efficacy of traditional medical treatment, or worsening of inflammation (1). In recent years, with the increase of bacterial resistance and emergence of new pathogens, the incidence of refractory pneumonia in children has been increasing annually. The unsatisfactory efficacy of traditional empirical treatment poses a great challenge to the clinical treatment of refractory pneumonia (2). Therefore, the clinical consensus is to seek new effective treatments for this disease.

Bronchoalveolar lavage (BAL) is a new technology developed on the basis of fiberoptic bronchoscopy by injecting normal saline into the bronchoalveolar space, aspirating the lavage fluid with a bronchoscope, collecting the liquid from the alveolar surface [called bronchoalveolar lavage buffer (BALF)], and finally checking the cellular components and soluble substances in the BALF (3). However, there is currently some controversy regarding the clinical value of BAL in the treatment of refractory pneumonia in children. This study analyzed the clinical efficacy, inflammatory factors, and immune function of BAL treatment in children with refractory pneumonia, in order to provide new ideas for clinical treatment of this disease. We present the following article in accordance with the STROBE reporting checklist (available at: http://dx.doi.org/10.21037/tp-21-89).

\section{Methods}

\section{General information}

A total of 196 children with refractory pneumonia admitted to our hospital from July 2017 to January 2020 were selected as the research cohort. The inclusion criteria were as follows: (I) patients meet at least 1 of the following 3 criteria (4): (i) after clinical standard antibiotic treatment of $\geq 10$ days, the clinical manifestations such as cough and fever (body temperature above $30^{\circ} \mathrm{C}$ ) in the child are not significantly improved or even progressively worsened, and with lung X-ray [computed tomography (CT)] showing no change or aggravation; (ii) patients with multiple complications inside or outside the lungs (such as atelectasis, pleural effusion, central nervous system disease, skin rash, pericardial effusion, hepatosplenomegaly); (iii) children with refractory pneumonia for over 3 weeks. (II) the family members of the children are informed and signed the informed consent. The exclusion criteria were as follows: (I) children aged $>14$ or $<2$ years old, because after general anesthesia intubation, the bronchoscope cannot perform lavage through the intubation due to the small inner diameter of the trachea in children under 2 years old (5); (II) children with congenital lung dysplasia or other diseases such as lung mass; (III) dysfunction of heart, liver, kidney, or other important organs; (IV) coagulation dysfunction or other systemic infectious diseases; (V) poor compliance due to mental disorders. According to the difference of treatment methods, the participants were divided into the study group $(n=49)$ and the control group $(n=47)$. The general clinical data of patients in the 2 groups were not significantly different $(\mathrm{P}>0.05$, Table 1$)$.

\section{Treatment methods in the two groups}

Both groups of children received systemic anti-infective therapy with antibiotic, postural drainage, and symptomatic supportive treatment (such as resolving phlegm, antispasmodic, anti-asthmatic, atomization, strengthening nutritional support, encouraging children to cough and expectorate, correcting acid-base electrolyte imbalance).

Participants in the research group were administered with BAL treatment on the basis of the treatment mentioned above. Participants were routinely fasted for 4-6 hours before surgery, and received local anesthesia with $1 \%$ lidocaine in the nasopharyngeal area, and combined intravenous anesthesia with propofol, in the supine position. The appropriate fiberoptic bronchoscope was chosen according to 
the condition, actual situation, and individual developmental differences of the participants. The fiberoptic bronchoscope was introduced through the nasal cavity, with simultaneous anesthetizing. We carefully observed the status of the trachea, bronchus, and lobar segmental bronchus to the lesion location. Then, the tip of the fiberoptic bronchoscope was inserted into the bronchus of the infected lesion site and embedded into the lumen. About $5 \mathrm{~mL}$ of $37^{\circ} \mathrm{C}$ normal saline were injected for lavage, the lavage fluid was aspirated, and this was repeated 3 times in total. Lavage fluid of all participants was collected for sputum culture and drug sensitivity test, acid-fast staining, mycoplasma chlamydia DNA quantitative detection, and tuberculosis culture. For the lung segments with heavy secretions and severe inflammation, repeated pressure lavage was performed with lavage fluid $(50 \mathrm{~mL}$ of sterile normal saline $+80,000 \mathrm{U}$ of gentamicin + $5 \mathrm{mg}$ of dexamethasone, warmed to about $37^{\circ} \mathrm{C}$ ), to carry out alveolar lavage 3 times; participants with severe local inflammation or atelectasis were treated with $0.5-1 \mathrm{~mL} / \mathrm{kg}$ of normal saline at $37{ }^{\circ} \mathrm{C}$ per lavage. The total volume of lavage fluid should not have exceeded $3-5 \mathrm{~mL} / \mathrm{kg}$ (for body weight less than $20 \mathrm{~kg}$, the volume per lavage was $1 \mathrm{~mL} / \mathrm{kg}$; for body weight over $20 \mathrm{~kg}$, the volume per lavage was $20 \mathrm{~mL}$ ). The lavage fluid was aspirated immediately after being injected through the biopsy hole with a suction negative pressure of $100-150 \mathrm{mmHg}$, which was placed in a sterilized sputum collector for cytokine examination. Repeated washing until the secretions in the bronchial lumen at all levels were sucked up and the lavage fluid was clear; then sensitive antibiotics dissolved with normal saline at $37{ }^{\circ} \mathrm{C}$ were used to wash the lesions of the lung lobes 3-5 times. Finally, the condition of the lungs was checked, and the operation was completed after thorough aspiration of the lavage fluid.

\section{Observation indicators}

The observation indicators of this study were as follows: (I) time for fever subsidence, time for cough relief, and length of hospital stay; (II) collection of $3 \mathrm{~mL}$ of fasting cubital venous blood before treatment, 3 days, and 1 week after treatment, centrifuged $\left(4^{\circ} \mathrm{C}, 3,000 \mathrm{rpm}, 10 \mathrm{~min}\right)$ within 30 minutes of blood collection, and the supernatant was removed for further determination. Double antibody sandwich enzyme-linked immunosorbent assay (EIISA) was performed to detect the levels of interleukin-6 (IL-6) and tumor necrosis factor- $\alpha(\mathrm{TNF}-\alpha)$. Immunoturbidimetric method was performed to detect the level of C-reactive protein (CRP). All detection kits were purchased from
Shanghai Enzyme Link Biotechnology Co., Ltd., and all the experiments were operated in accordance with the manufacturer instructions of the respective kits. The levels of IL-6, CRP and TNF- $\alpha$ in bronchoalveolar lavage fluid were measured by EIISA. (III) Immune function: the peripheral venous blood of the participants was drawn before treatment, 3 days, and 1 week after treatment, and the levels of immunoglobulin A ( $\operatorname{IgA})$, immunoglobulin $\mathrm{G}(\mathrm{IgG})$, and immunoglobin $\mathrm{M}(\operatorname{IgM})$ were detected by fluorescent immunolabeling method. (IV) Pulmonary ventilation function indicators: $3-5 \mathrm{~mL}$ of arterial blood was collected from participants of the 2 groups before treatment, 3 days, and 1 week after treatment, and the arterial blood samples were analyzed by the Danish Renault ABL800 FLEX blood gas analyzer (Shanghai Radiometer Medical Equipment, Shanghai, China) to detect blood oxygen partial pressure $\left(\mathrm{PaO}_{2}\right)$, mean airway pressure (mPaw), and inspired oxygen concentration $\left(\mathrm{FiO}_{2}\right)$. The oxygenation index $(\mathrm{OI})$ could be calculated with the formula: $\mathrm{OI}=\left(\mathrm{PaO}_{2} \times \mathrm{mPaw}\right) / \mathrm{FiO}_{2}(6)$; The lung dynamic compliance (Cdyn) and work of breathing (WOB) were detected using the ResMed ventilator (ResMed Medical Device Co., Ltd, Beijing, China). (V) Complications.

\section{Efficacy criteria}

According to the efficacy criteria (7), treatment was deemed significantly effective by the following outcomes: pneumonia symptoms such as cough and sputum were significantly reduced or disappeared, body temperature returned to normal, blood indexes returned to normal in the laboratory test, sputum test result became negative, and the imaging examination showed that the lesion was absorbed and completely dissipated. Treatment was deemed effective based on the following: symptoms of pneumonia such as cough and sputum were alleviated, body temperature returned to normal or slightly higher than normal, blood indexes returned to normal in the laboratory test, sputum test result became negative, and imaging examination showed partial absorption of inflammatory lesions. Treatment was deemed ineffective based on the following: no improvement in pneumonia symptoms and signs, laboratory examination and imaging examination showed no improvement, or even continued to deteriorate.

\section{Statistical analysis}

The data were statistically analyzed using the software 
Table 2 Comparison of fever remission time, cough relief time, and length of hospital stay between the 2 groups $\left(\bar{x}_{ \pm} \mathrm{S}, \mathrm{d}\right)$

\begin{tabular}{lccc}
\hline Group & Fever remission time $(\mathrm{d})$ & Cough relief time $(\mathrm{d})$ & Hospital stay length $(\mathrm{d})$ \\
\hline Study group $(\mathrm{n}=99)$ & $9.05 \pm 1.14$ & $10.63 \pm 1.35$ & $14.03 \pm 1.25$ \\
Control group $(\mathrm{n}=97)$ & $12.36 \pm 1.38$ & $13.95 \pm 1.87$ & $17.58 \pm 1.63$ \\
$\mathrm{t}$ value & 18.323 & 14.273 & 17.131 \\
$\mathrm{P}$ value & $<0.001$ & $<0.001$ & $<0.001$ \\
\hline
\end{tabular}

Table 3 Comparison of clinical efficacy between the 2 groups

\begin{tabular}{lcccc}
\hline Group & Significantly effective, $\mathrm{n}(\%)$ & Effective, $\mathrm{n}(\%)$ & Ineffective, $\mathrm{n}(\%)$ & Total effective rate, $\mathrm{n}(\%)$ \\
\hline Study group $(\mathrm{n}=99)$ & $61(61.62)$ & $36(36.36)$ & $2(2.02)$ & 97.98 \\
Control group $(\mathrm{n}=97)$ & $45(46.39)$ & $43(44.33)$ & $9(9.28)$ & 90.72 \\
$\chi^{2}$ & & & 4.872 & \\
$\mathrm{P}$ value & & 0.027 & \\
\hline
\end{tabular}

SPSS version 22.0 (IBM, Armonk, NY, USA). The count data were expressed as $\mathrm{n}(\%)$, and analyzed using the chisquared $\left(\chi^{2}\right)$ test; measurement data were described as the mean \pm standard deviation $(\bar{x} \pm s)$, and analyzed using the $t$-test. Results with $\mathrm{P}<0.05$ were considered statistically significant.

\section{Ethical statement}

The study was approved by Sunshine Union Hospital (NO.: [2021]14-8). All procedures performed in this study involving human participants were in accordance with the Declaration of Helsinki (as revised in 2013). The informed consent was taken from all the patients.

\section{Results}

Comparison of the time of fever remission, cough relief, and hospital stay

The fever remission time, cough relief time, and length of hospital stay of the study group were shorter than those of the control group $(\mathrm{P}<0.05$, Table 2$)$.

\section{Comparison of clinical efficacy between the 2 groups}

The total clinical effective rate of the study group (97.98\%) was significantly higher than that of the control group $(90.72 \%)(\mathrm{P}<0.05$, Table 3).
Comparison of inflammatory factor levels between the 2 groups before and after treatment

There was no significant difference in inflammatory factor levels before treatment $(\mathrm{P}>0.05)$, while the levels of IL-6, CRP, and TNF- $\alpha$ of both groups at 3 days after treatment were significantly decreased, and the lowest levels of these indicators appeared 1 week after treatment. Besides, the levels of inflammatory factors in the study group were lower than those in the control group at any time point after treatment $(\mathrm{P}<0.05$, Table 4).

\section{Comparison of the levels of IL-6, CRP and TNF- $\alpha$ in bronchoalveolar lavage fluid before and after treatment in the study group}

After 3 days of treatment, the levels of IL-6, CRP and TNF- $\alpha$ in bronchoalveolar lavage fluid in the study group were significantly lower than before treatment, and reached the lowest value after 1 week of treatment $(\mathrm{P}<0.05$, Table 5).

\section{Comparison of immune function indexes between the 2 groups before and after treatment}

There was no significant difference in the levels of immune function indexes (IgA, IgG, and $\operatorname{IgM}$ ) before and after treatment between the 2 groups $(\mathrm{P}>0.05)$. After 3 days of treatment, the levels of IgA and IgG in each group were 
Table 4 Comparison of inflammatory factor levels between the 2 groups before and after treatment $\left(\bar{x}_{ \pm} \mathrm{s}\right)$

\begin{tabular}{|c|c|c|c|c|c|c|c|c|c|}
\hline Group & \multicolumn{3}{|c|}{ IL-6 ( $\mu \mathrm{g} / \mathrm{L})$} & \multicolumn{3}{|c|}{ TNF- $\alpha(\mu \mathrm{g} / \mathrm{L})$} & \multicolumn{3}{|c|}{ CRP ( $\mu \mathrm{g} / \mathrm{L})$} \\
\hline $\begin{array}{l}\text { Study group } \\
(n=99)\end{array}$ & $5.09 \pm 1.95$ & $3.61 \pm 1.25^{\mathrm{a}}$ & $2.09 \pm 0.87^{\mathrm{ab}}$ & $0.97 \pm 0.32$ & $0.54 \pm 0.21^{a}$ & $0.18 \pm 0.06^{\mathrm{ab}}$ & $3.52 \pm 1.35$ & $1.56 \pm 1.42^{\mathrm{a}}$ & $0.78 \pm 0.41^{\mathrm{ab}}$ \\
\hline $\begin{array}{l}\text { Control group } \\
(\mathrm{n}=97)\end{array}$ & $5.12 \pm 1.98$ & $4.26 \pm 1.33^{\mathrm{a}}$ & $3.52 \pm 0.93^{a b}$ & $0.94 \pm 0.35$ & $0.75 \pm 0.26^{a}$ & $0.29 \pm 0.13^{\mathrm{ab}}$ & $3.56 \pm 1.38$ & $2.35 \pm 1.13^{\mathrm{a}}$ & $1.50 \pm 0.59^{\mathrm{ab}}$ \\
\hline t value & 0.107 & 3.526 & 11.119 & 0.626 & 6.227 & 7.631 & 0.205 & 4.304 & 9.938 \\
\hline$P$ value & 0.915 & 0.001 & $<0.001$ & 0.532 & $<0.001$ & $<0.001$ & 0.838 & $<0.001$ & $<0.001$ \\
\hline
\end{tabular}

${ }^{a}$, compared with the same group before treatment, $\mathrm{P}<0.05$; ${ }^{\mathrm{b}}$, compared with the same group 3 days after treatment, $\mathrm{P}<0.05$. IL-6, interleukin-6; TNF- $\alpha$, tumor necrosis factor- $\alpha$; CRP, C-reactive protein.

Table 5 IL-6, CRP and TNF- $\alpha$ levels in bronchoalveolar lavage fluid before and after treatment in the study group

\begin{tabular}{lccc}
\hline Time & IL-6 $(\mathrm{ng} / \mathrm{L})$ & CRP $(\mathrm{mg} / \mathrm{L})$ & TNF- $\alpha(\mathrm{ng} / \mathrm{L})$ \\
\hline Before treatment & $52.16 \pm 10.97$ & $87.97 \pm 5.21$ & $70.56 \pm 11.62$ \\
3 days after treatment & $97.98 \pm 5.87^{\mathrm{a}}$ & $50.98 \pm 7.12^{\mathrm{a}}$ & $54.10 \pm 5.18^{\mathrm{a}}$ \\
1 week after treatment & $23.61 \pm 3.58^{\mathrm{ab}}$ & $36.08 \pm 2.56^{\mathrm{ab}}$ & $30.89 \pm 2.74^{\mathrm{ab}}$ \\
$\mathrm{t}$ & 2494.13 & 2512.09 & 696.58 \\
$\mathrm{P}$ & $<0.001$ & $<0.001$ & $<0.001$
\end{tabular}

${ }^{\mathrm{a}}$, compared with before treatment, $\mathrm{P}<0.05 ;{ }^{\mathrm{b}}$, compared with the same group after 3 days after treatment, $\mathrm{P}<0.05$.

higher than before treatment, while the level of $\operatorname{IgM}$ was lower than before treatment, and the level of IgM reached the peak value (the lowest value) after 1 week of treatment. Meanwhile, the levels of IgA and IgG in the study group were higher than those in the control group at any time point after treatment, and the level of IgM was lower than that in the control group at any time point after treatment $(\mathrm{P}<0.05$, Table 6).

\section{Comparison of pulmonary ventilation function indexes between the 2 groups before and after treatment}

Before treatment, there was no significant difference in the levels of pulmonary ventilation function between the 2 groups $(\mathrm{P}>0.05)$, while 3 days after treatment, the levels of OI, Cdyn, and WOB were significantly higher than those before treatment, and reached the peak value 1 week after treatment. Besides, the lung ventilation index levels in the experimental group were higher than those in the control group at any time point after treatment $(\mathrm{P}<0.05$, Table 7).

\section{Complications}

During treatment, no serious complications occurred in the control group. In the study group, there was 1 case of transient supraventricular tachycardia, and 2 cases of oxygen desaturation. The complications were improved by suspending operation and administering high-concentration oxygen inhalation. There was no significant difference in complication rates between the study group $(3.03 \%)$ and the control group $(0.00 \%),\left(\chi^{2}=2.985, P=0.084\right)$.

\section{Discussion}

Refractory pneumonia in children is a special type of pneumonia with serious symptoms and a protracted disease course; it cannot be satisfactorily treated by conventional treatment methods, and recurrence happens easily $(8,9)$. It has been clinically determined that due to children's underdevelopment of efficient expectoration, and the inability to administer regular anti-inflammatory treatment in a timely and effective manner, the condition of some children may gradually deteriorate, causing a variety of 
Table 6 Comparison of the levels of immune function indexes between the 2 groups before and after treatment $(\bar{x} \pm \mathrm{s}, \mathrm{g} / \mathrm{L})$

\begin{tabular}{|c|c|c|c|c|c|c|c|c|c|}
\hline Group & \multicolumn{3}{|c|}{$\lg \mathrm{A}$} & \multicolumn{3}{|c|}{$\lg G$} & \multicolumn{3}{|c|}{$\lg M$} \\
\hline Control group $(n=97)$ & $2.65 \pm 1.25$ & $2.90 \pm 1.29^{a}$ & $3.51 \pm 1.31^{\mathrm{ab}}$ & $6.35 \pm 2.12$ & $7.30 \pm 2.05^{a}$ & $8.21 \pm 2.15^{\mathrm{ab}}$ & $1.89 \pm 0.65$ & $1.12 \pm 0.45^{\mathrm{a}}$ & $0.95 \pm 0.43^{\mathrm{ab}}$ \\
\hline
\end{tabular}

${ }^{a}$, compared with the same group before treatment, $\mathrm{P}<0.05$; ${ }^{\mathrm{b}}$, compared with the same group 3 days after treatment, $\mathrm{P}<0.05$. IGA, immunoglobulin A; IgG, immunoglobulin G; IgM, immunoglobulin M.

Table 7 Comparison of pulmonary ventilation function indexes between the 2 groups before and after treatment $\left(\bar{x}_{ \pm s}\right)$

\begin{tabular}{|c|c|c|c|c|c|c|c|c|c|}
\hline Group & \multicolumn{3}{|c|}{ Ol (mmHg) } & \multicolumn{3}{|c|}{ Cdyn $\left(\mathrm{mL} / \mathrm{cmH}_{2} \mathrm{O}\right)$} & \multicolumn{3}{|c|}{ WOB (J/L) } \\
\hline $\begin{array}{l}\text { Control } \\
\text { group }(n=97)\end{array}$ & $248.51 \pm 23.17$ & $276.59 \pm 21.30^{a}$ & $305.85 \pm 15.16^{\mathrm{ab}}$ & $20.39 \pm 2.78$ & $23.69 \pm 2.35^{\mathrm{a}}$ & $30.05 \pm 2.31^{\mathrm{ab}}$ & $1.98 \pm 0.34$ & $5.18 \pm 1.33^{\mathrm{a}}$ & $8.41 \pm 1.95^{\mathrm{ab}}$ \\
\hline t value & 0.287 & 6.235 & 9.245 & 0.026 & 14.330 & 15.538 & 0.600 & 10.470 & 12.783 \\
\hline$P$ value & 0.774 & $<0.001$ & $<0.001$ & 0.980 & $<0.001$ & $<0.001$ & 0.550 & $<0.001$ & $<0.001$ \\
\hline
\end{tabular}

${ }^{a}$, compared with the same group before treatment, $\mathrm{P}<0.05 ;{ }^{\mathrm{b}}$, compared with the same group 3 days after treatment, $\mathrm{P}<0.05$. OI, oxygenation index; Cdyn, lung dynamic compliance; WOB, work of breathing.

serious consequences (10). Therefore, in recent years, some experts have pointed out that the focus of clinical treatment is to choose targeted antibiotics, relieve narrow airway obstruction, and adequately drain bronchial secretions (11).

Since its application in clinical practice, fiberoptic bronchoscopy has gradually become an important tool for clinical diagnosis and treatment (12). Compared with conventional medical treatment, fiberoptic bronchoscopy and bronchoalveolar lavage have many advantages in the treatment of severe pneumonia in children. On the one hand, performing bronchoscopy and related treatment can not only aspirate deep sputum on the basis of detailed observation of the lesions, and then the deep sputum can be collected for bacterial culture and drug susceptibility testing, which is conducive to the clinical selection of antibiotics. Implementing BAL can also remove the causes of lumen blockage, such as phlegm deposits, to achieve the objective of adequate drainage (13). On the other hand, the method of using bronchoscopy makes it possible to operate under direct vision, which can avoid or reduce damage of the tracheal mucosa, and can quickly improve the hypoxic state in a short time. In addition, after repeated lavage with local normal saline and chymotrypsin under fibrobronchoscope, brush for nips and scrub, inflammatory secretions, purulent moss and sputum plugs, granulation tissue and harmful pathogenic microorganisms in the airway can be fully removed, and clinical symptoms can be quickly alleviated and obstruction can be removed. thereby shortening the lung recruitment time (14).

In this study, fiberoptic bronchoscopy was used to perform BAL in children with refractory pneumonia. During the operation, normal saline and/or antibiotics, as well as adrenocorticoid drugs were used to fully lavage the blocked bronchial cavity. The narrow bronchus was dredged many times with a bronchoscope of the corresponding caliber to achieve the aim of reducing the production of pulmonary endocrine fluid (15). The results of this study showed that the total clinical effective rate of the study group was significantly higher than that of the control group $(\mathrm{P}<0.05)$, and the length of hospitalization (indicated by 
relief of the clinic symptom) was significantly shorter than that of the control group, indicating that BAL treatment has a significant effect on relief of the clinical symptoms. In addition, the simultaneous local infusion of antibiotics and dexamethasone during BAL can effectively increase the anti-inflammatory effect due to the significant increase of the drug concentration at the lesion site $(16,17)$. In addition, the high concentration of hormones in the lesion site has anti-inflammatory and anti-allergic effects, and relieves bronchospasm, which can promote the recovery of the diseased tissues and achieve better therapeutic effects (18). Our results confirmed the factors above, because the improvement of inflammatory factors, immune function, and lung ventilation function indexes in the study group were more significant in the study group compared to the control group. In addition, the levels of IL-6, CRP and TNF- $\alpha$ in bronchoalveolar lavage fluid in the study group were significantly decreased after 3 days after treatment, and reached the lowest value after 1 week after treatment.

It is worth noting that as an invasive operation, BAL treatment is poorly performed among children, which might bring a certain procedural risk. Results in this study showed that participants in the study group experienced symptoms such as supraventricular tachycardia and decreased blood oxygen saturation during the operation. These complications indicate that the following tips should be heeded during the clinical application: (I) for younger children, general anesthesia is suggested, while for relatively older children, the treatment can be performed on the basis of proper sedation; (II) rescue drugs should be prepared in advance before airway lavage, and the theatre should be equipped with complete electrocardiograph (ECG), blood pressure, and blood oxygen monitoring; (III) the surgeon must strictly follow the principles of aseptic surgery; (IV) for patients with a history of high airway response, $\beta 2$ receptor agonists can be inhaled before operation to relieve intraoperative bronchospasm; (V) BAL is not suitable for patients without cough reflexes $(19,20)$.

In summary, BAL therapy can effectively control the inflammatory response in children with refractory pneumonia, improve their immune function, and improve their lung ventilation function. Owing to the remarkable clinical efficacy, BAL is worthy of popularization.

\section{Acknowledgments}

Funding: This study was approved by the Scientific Research Program of Weifang Health Commission
(WFWSJK-2020-098).

\section{Footnote}

Reporting Checklist: The authors have completed the STROBE reporting checklist. Available at: http://dx.doi. org/10.21037/tp-21-89

Data Sharing Statement: Available at: http://dx.doi. org/10.21037/tp-21-89

Conflicts of Interest: All authors have completed the ICMJE uniform disclosure form (available at: http://dx.doi. org/10.21037/tp-21-89). The authors have no conflicts of interest to declare.

Ethical Statement: The authors are accountable for all aspects of the work in ensuring that questions related to the accuracy or integrity of any part of the work are appropriately investigated and resolved. The study was approved by Sunshine Union Hospital (NO.: [2021]14-8). All procedures performed in this study involving human participants were in accordance with the Declaration of Helsinki (as revised in 2013). The informed consent was taken from all the patients.

Open Access Statement: This is an Open Access article distributed in accordance with the Creative Commons Attribution-NonCommercial-NoDerivs 4.0 International License (CC BY-NC-ND 4.0), which permits the noncommercial replication and distribution of the article with the strict proviso that no changes or edits are made and the original work is properly cited (including links to both the formal publication through the relevant DOI and the license). See: https://creativecommons.org/licenses/by-nc-nd/4.0/.

\section{References}

1. Hotta T, Kurimoto N, Okimoto T, et al. New procedure of bronchoalveolar lavage using a balloon catheter in diffuse lung diseases. Respir Investig 2020;58:68-73.

2. Bollmann BA, Seeliger B, Drick N, et al. Cellular analysis in bronchoalveolar lavage: inherent limitations of current standard procedure. Eur Respir J 2017;49:1601844.

3. Walmsley S, Cruickshank-Quinn C, Quinn K, et al. A prototypic small molecule database for bronchoalveolar lavage-based metabolomics. Sci Data 2018;5:180060.

4. Hooi KS, Defarges AM, Sanchez AL, et al. Comparison 
of bronchoscopic and nonbronchoscopic bronchoalveolar lavage in healthy cats. Am J Vet Res 2018;79:1209-16.

5. Poletti V, Ravaglia C. Methodological issues are important in cannabinoids determination in bronchoalveolar lavage. Clin Chem Lab Med 2019;57:e41-2.

6. Zirlik S, Neurath MF, Meidenbauer N, et al. Identification of Bronchoalveolar Lavage Components Applying Confocal Laser Endomicroscopy. Med Sci Monit 2018;24:4198-203.

7. Royer S, Prescott HC. Next Steps for Confirming Bronchoalveolar Lavage Amlyase as an Useful Biomarker for Ventilator-Associated Pneumonia. Crit Care Med 2018;46:165-6.

8. Cullimore AM, Secombe CJ, Lester GD, et al. Bronchoalveolar lavage fluid cytology and airway hyper-reactivity in clinically normal horses. Aust Vet J 2018;96:291-6.

9. Pavelski M, Correa Leite N, Pedri E, et al. Singlealiquot, non-bronchoscopic bronchoalveolar lavage in the diagnosis of metastatic mammary tumours in dogs. J Small Anim Pract 2017;58:168-73.

10. Mo Y, Zhang Y, Zhang Q. Evaluation of Pulmonary Toxicity of Nanoparticles by Bronchoalveolar Lavage. Methods Mol Biol 2019;1894:313-22.

11. Dell'Orto V, Bourgeois-Nicolaos N, Rouard C, et al. Cell Count Analysis from Nonbronchoscopic Bronchoalveolar Lavage in Preterm Infants. J Pediatr 2018;200:30-37.e2.

12. Barton AK, Schulze T, Doherr MG, et al. Influence of bronchoalveolar lavage on thoracic radiography in the

Cite this article as: Pei M, Jiang P, Wang T, Xia C, Hou R, Sun A, Zou H. Effect of bronchoalveolar lavage on the clinical efficacy, inflammatory factors, and immune function in the treatment of refractory pneumonia in children. Transl Pediatr 2021;10(4):921-928. doi: 10.21037/tp-21-89 horse. J Vet Sci 2018;19:563-9.

13. Hansen T, Constantin C, Weber M, et al. Bronchoalveolar lavage in hairy cell leukemia with pulmonary infiltration. Pathologe 2019;40:529-33.

14. Couetil LL, Thompson CA. Airway Diagnostics: Bronchoalveolar Lavage, Tracheal Wash, and Pleural Fluid. Vet Clin North Am Equine Pract 2020;36:87-103.

15. Di ME, Yang D, Di YP. Using Bronchoalveolar Lavage to Evaluate Changes in Pulmonary Diseases. Methods Mol Biol 2020;2102:117-28.

16. Yu Y, Liu C, Zhang Z, et al. Bronchoalveolar lavage fluid dilution in ICU patients: what we should know and what we should do. Crit Care 2019;23:23.

17. Speck NE, Schuurmans MM, Benden C, et al. Plasma and bronchoalveolar lavage samples in acute lung allograft rejection: the potential role of cytokines as diagnostic markers. Respir Res 2017;18:151.

18. Baldi M, Sehgal IS, Dhooria S, et al. Pneumothorax After a Bronchoalveolar Lavage. J Bronchology Interv Pulmonol 2018;25:e45-6.

19. Van Hoecke L, Job ER, Saelens X, et al. Bronchoalveolar Lavage of Murine Lungs to Analyze Inflammatory Cell Infiltration. J Vis Exp 2017;54:55398.

20. Gharsalli H, Mlika M, Sahnoun I, et al. The utility of bronchoalveolar lavage in the evaluation of interstitial lung diseases: A clinicopathological perspective. Semin Diagn Pathol 2018;35:280-7.

(English Language Editor: J. Jones) 